\title{
Randomized, double-blind, placebo-controlled trial of arimoclomol in rapidly progressive SOD1 ALS
}

Michael Benatar, MD, PhD, Joanne Wuu, ScM, Peter M. Andersen, MD, PhD, Nazem Atassi, MD, William David, MD, Merit Cudkowicz, MD, and David Schoenfeld, PhD

Neurology ${ }^{\circledR}$ 2018;90:e565-e574. doi:10.1212/WNL.0000000000004960

\section{Abstract \\ Objective}

To examine the safety and tolerability as well as the preliminary efficacy of arimoclomol, a heat shock protein co-inducer that promotes nascent protein folding, in patients with rapidly progressive SOD1 amyotrophic lateral sclerosis (ALS).

\section{Methods}

This was a double-blind, placebo-controlled trial in which patients with rapidly progressive SOD1mutant ALS were randomized 1:1 to receive arimoclomol $200 \mathrm{mg}$ tid or matching placebo for up to 12 months. Study procedures were performed using a mix of in-person and remote assessments. Primary outcome was safety and tolerability. Secondary outcome was efficacy, with survival as the principal measure. Additional efficacy measures were the rates of decline of the Revised ALS Functional Rating Scale (ALSFRS-R) and percent predicted forced expiratory volume in 6 seconds (FEV6), and the Combined Assessment of Function and Survival (CAFS).

\section{Results}

Thirty-eight participants were randomized. Thirty-six (19 placebo, 17 arimoclomol) were included in the prespecified intent-to-treat analysis. Apart from respiratory function, groups were generally well-balanced at baseline. Adverse events occurred infrequently, and were usually mild and deemed unlikely or not related to study drug. Adjusting for riluzole and baseline ALSFRS-R, survival favored arimoclomol with a hazard ratio of 0.77 ( $95 \%$ confidence interval [CI] 0.32-1.80). ALSFRS-R and FEV6 declined more slowly in the arimoclomol group, with treatment differences of 0.5 point/month (95\% CI -0.63 to 1.63 ) and 1.24 percent predicted/month (95\% CI -2.77 to 5.25 ), respectively, and the CAFS similarly favored arimoclomol.

\section{Conclusions}

This study provides Class II evidence that arimoclomol is safe and well-tolerated at a dosage of $200 \mathrm{mg}$ tid for up to 12 months. Although not powered for therapeutic effect, the consistency of results across the range of prespecified efficacy outcome measures suggests a possible therapeutic benefit of arimoclomol.

\section{Clinicaltrials.gov identifier NCT00706147.}

\section{Classification of evidence}

This study provides Class II evidence that arimoclomol is safe and well-tolerated at a dosage of $200 \mathrm{mg}$ tid for up to 12 months. The study lacked the precision to conclude, or to exclude, an important therapeutic benefit of arimoclomol.

\author{
Correspondence \\ Dr. Benatar \\ mbenatar@med.miami. \\ edu
}

MORE ONLINE

$\rightarrow$ Class of evidence

NPub.org/coe

From the Department of Neurology (M.B., J.W.), University of Miami, FL; Department of Pharmacology and Clinical Neuroscience (P.M.A.), Umeå University, Sweden; Department of Neurology (N.A., W.D., M.C.), Massachusetts General Hospital (D.S.), Harvard Medical School; and Department of Biostatistics (D.S.), Harvard Chan School of Public Health, Boston, MA.

Go to Neurology.org/N for full disclosures. Funding information and disclosures deemed relevant by the authors, if any, are provided at the end of the article. 


\section{Glossary}

AE = adverse event; ALS = amyotrophic lateral sclerosis; ALSFRS-R = Revised ALS Functional Rating Scale; CAFS = Combined Assessment of Function and Survival; CI = confidence interval; CTCAE = Common Terminology Criteria for Adverse Events; DSMB = Data Safety Monitoring Board; EDC = electronic data capture; FEV6 = forced expiratory volume in 6 seconds; HR = hazard ratio; HSP = heat shock protein; IND = Investigational New Drug; IRB = institutional review board; MGH = Massachusetts General Hospital; PAV = permanent assisted ventilation; SAE = serious adverse event; SOD1 = CuZnsuperoxide dismutase; SVC = slow vital capacity.

Amyotrophic lateral sclerosis (ALS) is characterized by the formation of cytosolic aggregates that contain specific misfolded proteins in selected neuronal and glia cells. ${ }^{1}$ There is mounting evidence that these aggregates play a pathogenic role in disease initiation and propagation. ${ }^{2,3}$ Mutations in the gene encoding CuZn-superoxide dismutase (SOD1), the second most common identified cause of ALS, make the SOD1 protein more prone to aggregation, resulting in the deposition of cellular inclusions that contain misfolded SOD1 aggregates. ${ }^{4}$ With the goal of targeting the formation of such pathogenic aggregates, we selected arimoclomol (CytRx, Los Angeles, $\mathrm{CA}$; and Orphazyme, Copenhagen, Denmark) for evaluation in patients with rapidly progressive ALS caused by SOD1 mutations. Arimoclomol is a co-inducer of the heat shock protein (HSP) response $\mathrm{e}^{5-7}$ and promotes natural folding of nascent proteins and refolding of misfolded proteins. $^{8}$ Our choice of arimoclomol was further supported by evidence of meaningful therapeutic effect in methodologically rigorous studies in the G93A SOD1 mouse $^{7,9}$; its good safety record (up to $300 \mathrm{mg} /$ day) for a short period of time ( 12 weeks) in patients with ALS; and evidence of good penetration across the blood-brain barrier. $^{10}$

Since ALS is an etiologically, genetically, and phenotypically heterogeneous syndrome, ${ }^{11,12}$ we elected to focus exclusively on patients with ALS with a subset of SOD1 mutations that result in unstable SOD 1 proteins ${ }^{13}$ and are associated with a uniformly rapid rate of disease progression. ${ }^{14}$ We were cognizant that rapid disease progression would yield both advantages (e.g., large degree of measurable functional decline) and disadvantages (e.g., a highly aggressive form of disease might be most impervious to therapeutic efforts). We also recognized that the rapid accumulation of physical disability could limit participants' ability to travel for study visits, and that recruitment would be challenging for this ultrarare population. For these reasons, this study was originally proposed as an adaptive design, seamless, phase II/III, randomized, double-blind, placebo-controlled trial, with remote assessment of outcomes. The initial goals were to show safety/tolerability (phase II) and then efficacy (phase III). Slow recruitment, however, necessitated an administrative decision to close the trial after completion of phase
II. Here we report the safety and efficacy data from the completed phase II component of this trial.

\section{Methods}

\section{Standard protocol approvals, registrations, and patient consents}

Institutional review board (IRB) approval was obtained at each study center, and all participants provided written informed consent. The trial was registered on clinicaltrials.gov (NCT00706147).

\section{Study design and participants}

This randomized, double-blind, placebo-controlled trial was conducted at 2 sites and 3 academic medical centers in the United States (primary site: Emory University [until February 2011] then University of Miami [from March 2011]; second site: Massachusetts General Hospital $[\mathrm{MGH}])$. An independent medical monitor completed regular review of laboratory reports and adverse events (AEs), as well as realtime review of serious AEs (SAEs). Eligibility criteria (table e-1, links.lww.com/WNL/A135) aimed to enroll, from across the United States and Canada, a population relatively early in the course of ALS caused by SOD1 mutations associated with rapidly progressive disease.

\section{Randomization and blinding}

Randomization (1:1 to arimoclomol or matching placebo) was stratified by riluzole use and in block size of 2 within each stratum, and implemented using a central web-based electronic data capture (EDC) system managed by the Neurologic Clinical Research Institute Data Management Center at MGH. The randomization schedule, generated by a study statistician (J.W.), was provided to each research pharmacy. At randomization, the EDC assigned a participant identification number, which the site coordinator submitted to the research pharmacy for drug dispensing. Encapsulated placebo was matched in color and appearance to active drug. Except for the research pharmacists, pharmacy monitors, and study statisticians, all other personnel and study participants were blinded to treatment assignments.

\section{Procedures}

Arimoclomol and matching placebo were prepared and packaged by the CytRx Corporation (Los Angeles, CA). The 
research pharmacy of the primary site labeled and distributed investigational product to the second study site. When the first participants were randomized (February 2009), the highest dose permitted under the active Investigational New Drug (IND) was $100 \mathrm{mg}$ tid. In May 2010, after enrollment of the first 16 participants (of whom 8 were on arimoclomol, including 1 who was subsequently excluded per protocol), the Food and Drug Administration approved the use of $200 \mathrm{mg}$ tid. Dosage was increased to this level for all active participants (which for the arimoclomol group included 3 initially started at $100 \mathrm{mg}$ tid), and all newly enrolled participants received $200 \mathrm{mg}$ tid after IRB approval of the revised protocol. All data were analyzed following the intent-to-treat principle.

Knowing that participants, to be recruited across a broad geographic area, would accumulate physical disability quickly, we anticipated the challenges that participants would face in order to travel to a study site. By design, therefore, assessments were performed in person only at baseline and month 2 , with remote assessments planned for all other visits. Neurologic examination, motor unit number estimation, and slow vital capacity (SVC) could only be performed in person. Other assessments, conducted at all visits (in person and remotely), included vital signs; blood and urine for safety laboratories; Revised ALS Functional Rating Scale (ALSFRS-R), which has been validated for telephone administration ${ }^{15}$; and the forced expiratory volume in 6 seconds (FEV6). ${ }^{16}$ In addition, AEs, concomitant medications, study drug dose management, use of ventilatory support, and key study events were recorded at all visits.

Operationalization of remote assessments posed logistical challenges that required the introduction of 2 innovative features: (1) the collection of vital signs and blood/urine for safety laboratories in participants' homes: this was accomplished using the services of a mobile medical provider, Examination Management Services, Inc.; and (2) the use of FEV6 as the principal measure of respiratory function: the key advantage of FEV6 over SVC- and indeed, a necessity for this study - is that FEV6 may be self-administered by the participant using a low-cost portable device (Piko-6; nSpire Health, Inc., Longmont, CO). The device digitally displayed the FEV6 value, which the participant then reported to the study coordinator. Our use of the FEV6 in this way allowed for remote assessment of respiratory function, which we would otherwise not have been able to collect in this trial. Reproducibility and normative data for FEV6 are established. ${ }^{17}$

\section{Outcomes}

The primary outcome measure was originally designated as the ALSFRS-R rate of decline over 12 months, with survival (defined as permanent assisted ventilation $[\mathrm{PAV}]$ and tracheostomy-free survival) and FEV6 rate of decline as secondary measures. Given the higher than expected mortality observed in the combined groups in the blinded data, the principal efficacy measure was changed to survival in February 2014 with approval of the Data Safety Monitoring Board
(DSMB). Moreover, following the administrative decision to close the trial early, safety became the designated primary outcome, with efficacy secondary. These revisions to the protocol and statistical analysis plan were submitted under IND 101,942.

The primary endpoint of safety and tolerability was based on the frequency of AEs, abnormal vital signs, and abnormal laboratory studies above or below predefined alert levels. AEs and SAEs were categorized according to the Common Terminology Criteria for Adverse Events (CTCAE) and rated for severity and relatedness to study drug. In summarizing AEs: (1) if a participant experienced multiple occurrences of the same event, only the occurrence with the worst severity (or highest degree of relatedness to study drug) was counted; (2) CTCAE events were further classified into subgroups (AE type); e.g., pneumonia and bronchitis were both classified as upper/lower respiratory infection.

For efficacy, the principal outcome measure was PAV- and tracheostomy-free survival time, calculated from baseline to PAV (defined as first of 7 consecutive days when PAV was used $>22$ hours/d) or tracheostomy, date of death (if no PAV or tracheostomy), or date of last available follow-up/study contact (if still PAV- and tracheostomy-free by then). Participants not reaching survival endpoints were censored. Secondary efficacy measures included ALSFRS-R rate of decline (points/month), FEV6 rate of decline (\% predicted/ month), and joint rank scores of the Combined Assessment of Function and Survival (CAFS), which considers both ALSFRS-R rate of decline and survival.

\section{Sample size and statistical analyses}

With insufficient published data to establish a fixed sample size, we initially proposed a seamless adaptive design using methods described by Fisher, ${ }^{18}$ with phase III sample size to be re-estimated at the end of phase II, once the first 30 participants had completed at least 6 months of follow-up. The phase II target sample size of 30 was based on our consideration of the acceptable 6-month treatment failure rate in the arimoclomol group, with treatment failure defined as failure to remain on the originally assigned treatment and dose due to occurrence of an AE. Specifically, in the 15 arimoclomol participants we would estimate the $80 \%$ confidence interval (CI) of their 6-month treatment failure rate, which was expected to be $<40 \%$ based on the preliminary estimate of $13.6 \%$ in a prior arimoclomol trial. ${ }^{10}$ The acceptance of such a high rate of treatment failure (and wide $\mathrm{CI}$ ) was justified by the inexorably progressive nature of the disease and the absence of any known effective therapy. We prespecified that we would consider arimoclomol tolerable if the upper bound of this CI was $<40 \%$. At the end of phase II, we were to utilize all available data (up to 12 months of follow-up) to estimate the number of additional participants needed in phase III in order to detect, with $80 \%$ power and a 2 -sided $p=0.05$ significance level, a treatment difference of $30 \%$ based on ALSFRS-R rate of decline, which was the difference deemed clinically 
meaningful and had been used in previous trials. ${ }^{19}$ The trial, however, was closed before sample size re-estimation.

All 36 eligible participants who completed at least one followup visit were included in the intent-to-treat analysis. The only predefined subgroup was the A4V SOD1 mutation carriers, whom we expected to be the largest genetic subgroup and to exhibit a uniformly aggressive disease course. An independent DSMB performed periodic review of cumulative safety data and made recommendations to the principal investigator regarding trial continuation.

PAV- and tracheostomy-free survival was first summarized by Kaplan-Meier survival estimates and compared between treatment groups by Wilcoxon and log-rank tests, then analyzed using a proportional hazards model with riluzole use and baseline ALSFRS-R as prespecified covariates. ALSFRS-R and FEV6 rates of decline were compared between groups by mixed model analysis with a random intercept and slope, and the outcome measure at each visit as dependent variable. The independent variables were time and time-treatment interaction, with the test of treatment effect based on the time-treatment interaction. In secondary analyses, a quadratic term for time was included, as suggested by the finding of another ALS trial. ${ }^{20}$ In addition, 2 analyses that combine survival and ALSFRS-R rate of decline were performed. The CAFS joint rank scores ${ }^{21}$ were compiled for each participant and compared between groups by 2 -sample $t$ test. Treatment effect on the ALSFRS-R rate of decline, as well as any treatment effect on survival that is mediated through the ALSFRS-R, were estimated by the Vonesh shared parameter model. $^{22}$ Numerical time, based on actual number of days between baseline and each follow-up visit, was used in the survival, mixed model, and Vonesh analyses. For CAFS, survival times and ALSFRS-R rates of decline were obtained using numerical time, but the participant-to-participant comparisons made at nominal time points. Baseline covariate adjustment for potential imbalance between groups was considered. All analyses were performed using SAS 9.3.

\section{Role of the funding source}

None of the funding sources played any role in the design, analysis, or interpretation of data. The trial was conducted under the auspice of an investigator-sponsored IND, referencing the parent IND initially held by the CytRx Corporation and, after May 2011, by Orphazyme ApS (Copenhagen, Denmark). Neither CytRx nor Orphazyme played any role in trial design/implementation or in data analysis/publication.

\section{Results}

\section{Participants}

Enrollment was open between December 2008 and June 2014. The administrative decision to close the trial early

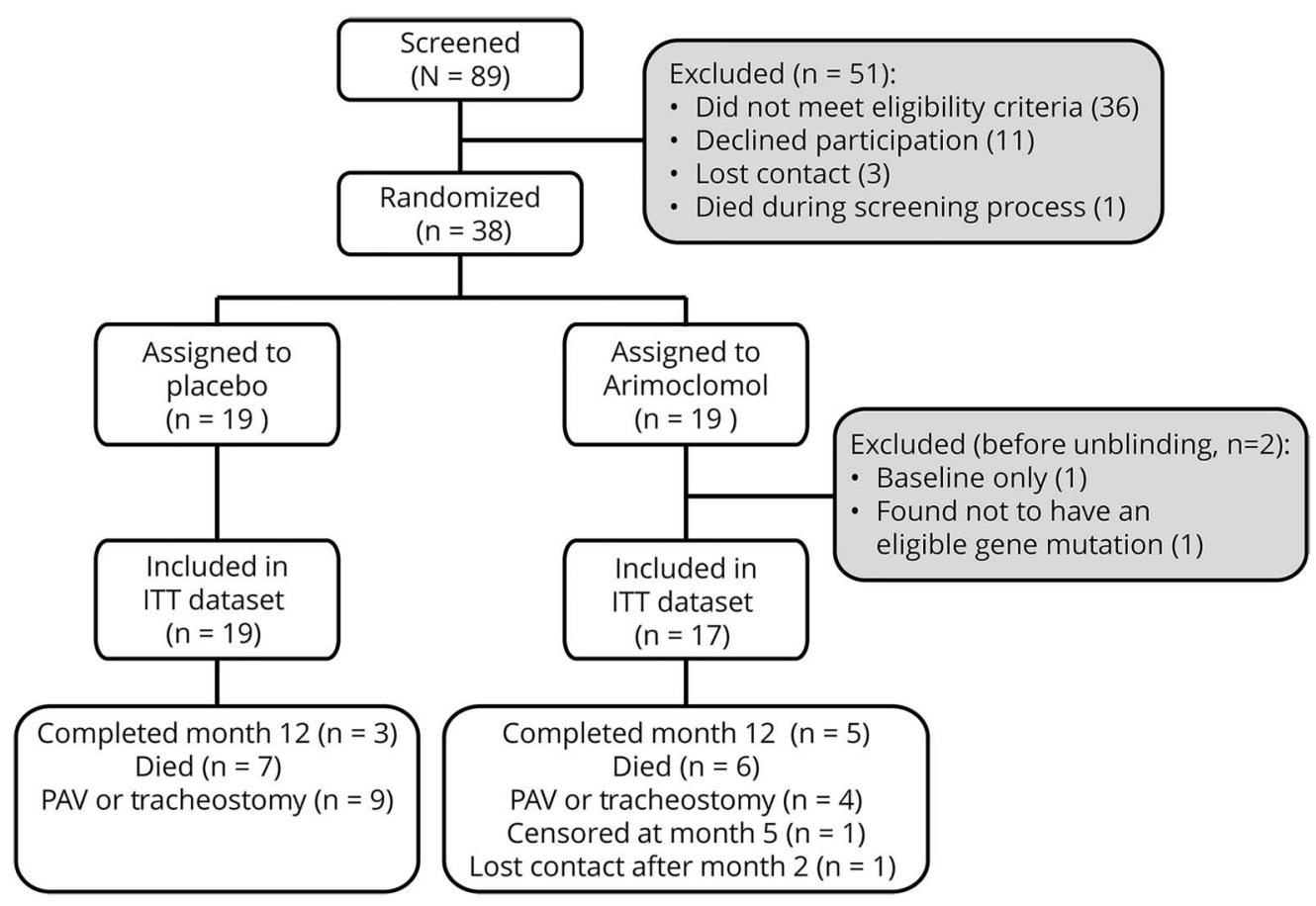

There were 2 patients in the arimoclomol group who were excluded from the intent-to-treat (ITT) analysis based on prespecified criteria: 1 patient died before completion of the month 1 visit; the other was found, after randomization, not to have a mutation in the SOD1 gene. The 1 patient in the arimoclomol group who was censored at month 5 had stopped drug at month 2 because of a skin rash thought probably related to study drug, and was then followed until month 5, when the participant enrolled in another clinical trial. PAV = permanent assisted ventilation. 
Table 1 Patient characteristics

\begin{tabular}{|c|c|c|c|c|}
\hline & \multicolumn{2}{|c|}{ All patients $(n=36)$} & \multicolumn{2}{|c|}{ A4V patients only $(n=26)$} \\
\hline & Placebo $(n=19)$ & Arimoclomol $(n=17)$ & Placebo $(n=13)$ & Arimoclomol $(n=13)$ \\
\hline \multicolumn{5}{|l|}{ Age, y } \\
\hline Mean \pm SD & $50.8 \pm 10.3$ & $51.1 \pm 12.3$ & $48.4 \pm 10.3$ & $52.8 \pm 13.2$ \\
\hline Median (range) & $52(25-65)$ & $50(29-75)$ & $51(25-62)$ & $55(29-75)$ \\
\hline \multicolumn{5}{|l|}{ Sex } \\
\hline Male & 7 & 6 & 6 & 4 \\
\hline Female & 12 & 11 & 7 & 9 \\
\hline \multicolumn{5}{|l|}{ SOD1 mutation } \\
\hline A4V & 13 & 13 & 13 & 13 \\
\hline G85R & 0 & 1 & - & - \\
\hline G141X & 1 & 0 & - & - \\
\hline I113T & 4 & 0 & - & - \\
\hline V14G & 1 & 0 & - & - \\
\hline V148G & 0 & 3 & - & - \\
\hline \multicolumn{5}{|l|}{ Site of onset } \\
\hline Limb & 16 & 15 & 11 & 12 \\
\hline Bulbar & 1 & 2 & 1 & 1 \\
\hline Thoracic & 2 & 0 & 1 & 0 \\
\hline \multicolumn{5}{|l|}{ Race $^{a}$} \\
\hline White & 19 & 17 & 13 & 13 \\
\hline Black/African American & 0 & 0 & 0 & 0 \\
\hline Asian & 0 & 0 & 0 & 0 \\
\hline Native American & 1 & 0 & 1 & 0 \\
\hline Unknown & 0 & 0 & 0 & 0 \\
\hline \multicolumn{5}{|l|}{ Ethnicity } \\
\hline Non-Hispanic or Latino & 19 & 17 & 13 & 13 \\
\hline \multicolumn{5}{|c|}{ Highest level of education completed } \\
\hline High school & 5 & 4 & 4 & 4 \\
\hline 2-Year college & 5 & 1 & 3 & 1 \\
\hline 4-Year college & 5 & 5 & 4 & 3 \\
\hline Master's & 3 & 7 & 1 & 5 \\
\hline Doctoral & 1 & 0 & 1 & 0 \\
\hline \multicolumn{5}{|c|}{ Months from onset to randomization ${ }^{b}$} \\
\hline Mean \pm SD & $8.0 \pm 3.6$ & $6.6 \pm 3.3$ & $8.5 \pm 4.0$ & $6.5 \pm 3.5$ \\
\hline Median (range) & $8.1(2.7-14.2)$ & $6.1(1.7-13.4)$ & $8.4(2.7-14.2)$ & $6.1(1.7-13.4)$ \\
\hline \multicolumn{5}{|l|}{$\Delta \mathbf{F R S}^{\mathbf{b}}$} \\
\hline Mean \pm SD & $1.24 \pm 0.93$ & $1.44 \pm 1.30$ & $1.41 \pm 1.00$ & $1.70 \pm 1.38$ \\
\hline Median (range) & $0.80(0.00-3.23)$ & $0.94(0.15-4.57)$ & $1.17(0.00-3.23)$ & $1.46(0.32-4.57)$ \\
\hline
\end{tabular}


Table 1 Patient characteristics (continued)

\begin{tabular}{|c|c|c|c|c|}
\hline & \multicolumn{2}{|c|}{ All patients $(n=36)$} & \multicolumn{2}{|c|}{ A4V patients only $(n=26)$} \\
\hline & Placebo $(n=19)$ & Arimoclomol $(n=17)$ & Placebo $(n=13)$ & Arimoclomol $(n=13)$ \\
\hline \multicolumn{5}{|c|}{ Months from diagnosis to randomization } \\
\hline Mean \pm SD & $3.1 \pm 2.3$ & $2.7 \pm 2.1$ & $2.8 \pm 1.7$ & $2.7 \pm 2.3$ \\
\hline Median (range) & $2.3(0.0-8.9)$ & $2.4(0.0-6.9)$ & $3.1(0.0-5.5)$ & $2.0(0.0-6.9)$ \\
\hline \multicolumn{5}{|l|}{ Taking riluzole } \\
\hline Yes & 11 & 11 & 7 & 10 \\
\hline No & 8 & 6 & 6 & 3 \\
\hline \multicolumn{5}{|c|}{ Baseline ALSFRS-R (total score) } \\
\hline Mean \pm SD & $37.2 \pm 8.2$ & $39.5 \pm 7.3$ & $37.0 \pm 7.8$ & $38.0 \pm 7.7$ \\
\hline Median (range) & $38(17-48)$ & $42(21-47)$ & $38(17-48)$ & $39(21-47)$ \\
\hline \multicolumn{5}{|c|}{ Baseline FEV6c (\%predicted) } \\
\hline Mean \pm SD & $69.3 \pm 28.5$ & $78.2 \pm 25.1$ & $73.4 \pm 33.1$ & $81.5 \pm 22.6$ \\
\hline Median (range) & $58.5(31-110)$ & $89(23-115)$ & $77.5(31-110)$ & $89(33-115)$ \\
\hline \multicolumn{5}{|c|}{ Baseline SVC (\% predicted) } \\
\hline Mean \pm SD & $78.5 \pm 25.3$ & $91.2 \pm 22.7$ & $82.5 \pm 27.1$ & $90.3 \pm 24.5$ \\
\hline Median (range) & $77(38-119)$ & $96(37-124)$ & $79(38-119)$ & $96(37-124)$ \\
\hline \multicolumn{5}{|c|}{ Baseline BMI, ${ }^{\mathrm{d}} \mathrm{kg} / \mathrm{m}^{2}$} \\
\hline Mean \pm SD & $28.4 \pm 5.3$ & $25.1 \pm 3.5$ & $29.3 \pm 4.5$ & $25.5 \pm 3.1$ \\
\hline Median (range) & $29.7(19.2-35.9)$ & $25.0(18.1-30.5)$ & $29.7(21.6-34.6)$ & $25.5(21.6-30.5)$ \\
\hline
\end{tabular}

Abbreviations: ALSFRS-R = Revised ALS Functional Rating Scale; BMI = body mass index; FEV6 = forced expiratory volume in 6 seconds; SVC = slow vital capacity.

$\triangle F R S=(48-$ ALSFRS-R at randomization $) /$ months from onset to randomization.

${ }^{a}$ Multiple categories possible.

${ }^{\mathrm{b}}$ Months from onset to randomization (and therefore $\triangle \mathrm{FRS}$ ) were not formally collected in the trial; they were later abstracted from medical records prior to unblinding and were unavailable for 2 patients on placebo. In addition, months from onset to randomization and $\Delta$ FRS of 2 other patients on placebo (1 A4V, 1 non-A4V) were excluded due to extreme and questionable values ( 30 months). With those 2 outliers included: months from onset to randomization, mean \pm $\mathrm{SD}$ (median [range]) $=10.9 \pm 8.9(8.7[2.7-35.2])$ for all placebo, $10.4 \pm 7.5(8.7[2.7-30.0])$ for A4V placebo. $\Delta$ FRS, mean \pm SD (median [range]) $=1.17 \pm 0.90(0.78$ [0.00-3.23]) for all placebo, $1.32 \pm 1.00(1.03[0.00-3.23])$ for A4V placebo.

'Baseline FEV6 not available for one patient on placebo.

${ }^{\mathrm{d}}$ Baseline weight (and therefore BMI) not available for one patient on arimoclomol.

was made by the steering committee, with input from the DSMB, while blinded to treatment group and study results. A total of 89 patients were screened, and 38 randomized (19/group). The absence of an SOD1 mutation $(\mathrm{n}=18)$ and the presence of an ineligible SOD1 mutation $(\mathrm{n}=8)$ were the most common reasons for ineligibility. The 38 randomized were recruited at Emory $(\mathrm{n}=15)$, University of Miami ( $n=13)$, and MGH $(n=10)$. Per protocol, 2 participants were excluded from analysis; one did not have an eligible SOD1 mutation and the other completed no follow-up visits after baseline (figure 1). Exclusions were made before unblinding, and both later revealed to be in the arimoclomol group. The analysis dataset thereby comprised 19 (53\%) participants on placebo and 17 (47\%) participants on arimoclomol. Groups were balanced at baseline except that FEV6 and SVC were higher in the arimoclomol group, while body mass index was higher in the placebo group (table 1).
Baseline SVC and FEV6 were strongly correlated $(r=0.89$, $p<0.0001)$.

\section{Safety}

AEs occurring in $\geq 10 \%(n \geq 4)$ of participants are summarized in table 2 . These were generally mild, occurred with similar frequency in the 2 arms, and were largely considered unrelated to study drug. Twenty-two SAEs were reported (15 in the placebo and 7 in the arimoclomol group), none of which were considered related to study drug. Abnormal vital signs or laboratory values were infrequent and occurred with comparable frequency in the 2 groups (table e-2, links.lww.com/ WNL/A135). A single participant stopped arimoclomol because of a skin rash (probably related to study drug).

\section{Efficacy}

While none of the efficacy analyses yielded statistically significant results, all point estimates favored arimoclomol but with CIs 
Table 2 Common Terminology Criteria for Adverse Events

\begin{tabular}{|c|c|c|c|c|c|c|c|c|c|c|c|c|c|c|c|c|}
\hline \multirow[b]{3}{*}{ Adverse event type } & \multicolumn{2}{|c|}{ Any occurrence, $\mathrm{n}(\%)$} & \multicolumn{2}{|c|}{ SAE, $n$} & \multicolumn{6}{|c|}{ By grade, $n$} & \multicolumn{6}{|c|}{ By relationship to study drug, $n$} \\
\hline & \multirow[b]{2}{*}{$\begin{array}{l}\text { Placebo } \\
(n=19)\end{array}$} & \multirow[b]{2}{*}{$\begin{array}{l}\text { Arimoclomol } \\
(n=17)\end{array}$} & \multirow[b]{2}{*}{$\begin{array}{l}\text { Placebo } \\
(n=19)\end{array}$} & \multirow[b]{2}{*}{$\begin{array}{l}\text { Arimoclomol } \\
(n=17)\end{array}$} & \multicolumn{3}{|c|}{ Placebo } & \multicolumn{3}{|c|}{ Arimoclomol } & \multicolumn{3}{|c|}{ Placebo } & \multicolumn{3}{|c|}{ Arimoclomol } \\
\hline & & & & & $1-2$ & 3 & $4-5$ & $1-2$ & 3 & 4-5 & $\begin{array}{l}\text { Not/ } \\
\text { unlike }\end{array}$ & Possible & Probable & $\begin{array}{l}\text { Not/ } \\
\text { unlike }\end{array}$ & Possible & Probable \\
\hline Dyspnea (shortness of breath) & $15(79)$ & $13(76)$ & 8 & 7 & 2 & 4 & 9 & 2 & 1 & 10 & 15 & - & - & 13 & - & - \\
\hline Respiratory: upper/lower & $12(63)$ & $6(35)$ & 2 & - & 10 & 2 & - & 6 & - & - & 12 & - & - & 6 & - & - \\
\hline $\begin{array}{l}\text { Upper gastrointestinal: nausea/ } \\
\text { anorexia/vomiting/duodenal ulcer }\end{array}$ & $9(47)$ & $8(47)$ & 1 & - & 7 & 2 & - & 8 & - & - & 9 & - & - & 4 & 2 & 2 \\
\hline $\begin{array}{l}\text { Muscle weakness: extremity/trunk/ } \\
\text { generalized }\end{array}$ & $7(37)$ & $8(47)$ & 1 & - & 4 & 2 & 1 & 3 & 4 & 1 & 7 & - & - & 8 & - & - \\
\hline Pain (other than headache) & $7(37)$ & $7(41)$ & - & - & 4 & 3 & - & 4 & 3 & - & 6 & 1 & - & 7 & - & - \\
\hline $\begin{array}{l}\text { Lower gastrointestinal: diarrhea/ } \\
\text { constipation }\end{array}$ & $5(26)$ & $7(41)$ & - & - & 5 & - & - & 7 & - & - & 3 & 2 & - & 5 & 2 & - \\
\hline Mood: anxiety/depression/agitation & $9(47)$ & $1(6)$ & - & - & 9 & - & - & - & 1 & - & 9 & - & - & 1 & - & - \\
\hline Headache & $7(37)$ & $2(12)$ & - & - & 5 & 1 & 1 & 2 & - & - & 5 & 2 & - & 1 & 1 & - \\
\hline Dysphagia (difficult swallowing) & $5(26)$ & $3(18)$ & 3 & - & 1 & 4 & - & - & 3 & - & 5 & - & - & 3 & - & - \\
\hline Fall & $4(21)$ & $4(24)$ & - & - & 3 & 1 & - & 4 & - & - & 4 & - & - & 4 & - & - \\
\hline Infection (other than respiratory) & $5(26)$ & $2(12)$ & - & - & 5 & - & - & 2 & - & - & 5 & - & - & 2 & - & - \\
\hline Insomnia & $3(16)$ & $4(24)$ & - & - & 3 & - & - & 3 & 1 & - & 3 & - & - & 4 & - & - \\
\hline Saliva: dry month/sialorrhea/thick & $3(16)$ & $4(24)$ & - & - & 3 & - & - & 4 & - & - & 2 & 1 & - & 3 & 1 & - \\
\hline Limb edema & $1(5)$ & $4(24)$ & - & - & 1 & - & - & 4 & - & - & 1 & - & - & 4 & - & - \\
\hline Diaphoresis (sweating) & $3(16)$ & $1(6)$ & - & - & 3 & - & - & 1 & - & - & 1 & 2 & - & 1 & - & - \\
\hline
\end{tabular}

Abbreviations: Not/unlike $=$ not related or unlikely to be related; $\mathrm{SAE}=$ serious adverse event.

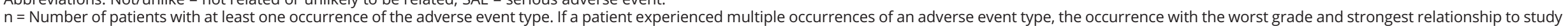
$\mathrm{n}=\mathrm{Nu}$ is $\mathrm{d}$. 
spanning unity. Kaplan-Meier plot shows a separation in survival curves, though the curves slightly crossed around 7.5 months (Wilcoxon test $p=0.27$, log-rank test $p=0.33$ ) (figure $2 \mathrm{~A}$ ). Similar results are observed in the A4V subgroup (13/group) (figure 2B). Survival estimates from the Cox proportional hazards model also favored arimoclomol compared to control, with an unadjusted hazard ratio (HR) of 0.67 (95\% CI 0.29-1.48, $p=$ 0.33); adjusting for baseline ALSFRS-R and riluzole, HR 0.77 (95\% CI 0.32-1.80, $p=0.55$ ). Adjustment for the baseline imbalance in respiratory function did not affect results (table e-3, links.lww.com/WNL/A135).

Among placebo-treated participants, ALSFRS-R declined by an average $( \pm S E)$ of $3.0 \pm 0.4$ points/month, compared to 2.5 \pm 0.4 points/month in the arimoclomol-treated group, a treatment difference of 0.5 points/month (95\% CI -0.63 to 1.63, $p=0.37)$. In the A4V subgroup, ALSFRS-R declined even faster, by an average of $3.6 \pm 0.5$ points/month in the placebo group but only $2.6 \pm 0.5$ points/month in the arimoclomol group, a treatment difference of 0.98 points $/$ month (95\% CI -0.28 to $2.24, p=0.12$ ). Notably, the magnitude of this difference is comparable to the average ALSFRS-R rate of decline in the untreated general ALS population $(1.02 \pm 2.3$ points/month). ${ }^{23}$ Moreover, the treatment difference of 0.5-1.0 points/month in ALSFRS-R rate of decline, though not statistically significant, translates into a clinically meaningful difference of 6-12 points over a 1-year period. Similar results were observed for the FEV6\% predicted rate of decline (table 3). Moreover, while adjustment for baseline ALSFRS-R or respiratory function variably increased or decreased the magnitude of treatment effect, overall results were unchanged (table e-3, links.lww.com/WNL/A135).
For the CAFS, which weights mortality as the more clinically important outcome and whose rank scores range from 1 (worst) to 36 (best), the average $( \pm \mathrm{SE})$ score in the arimoclomol group was $20.9 \pm 2.5$ compared to $16.3 \pm 2.4$ in the placebo group, with a potential treatment benefit of 4.57 points (95\% CI -2.50 to 11.64 ) (table 3). Moreover, in participant-to-participant comparison between the 2 groups, the arimoclomol group had a clinically significant win ratio of 1.69. ${ }^{24}$ The Vonesh model, on the other hand, yielded a treatment difference of $0.77 \pm 0.54$ points/month (95\% CI -0.33 to $1.86, p=0.16$ ) in ALSFRS-R rate of decline, whereas the direct effect of treatment on survival was not significant ( $p$ $=0.62$ ). This would indicate that the possible survival benefit of arimoclomol was mediated through a slowed decline of the ALSFRS-R rather than through an independent effect on survival.

\section{Discussion}

Arimoclomol was safe and well-tolerated at a dose of $200 \mathrm{mg}$ tid. While not powered to detect a statistically significant therapeutic effect, the consistency of results across all prespecified efficacy measures suggests a possible therapeutic benefit of arimoclomol in the overall study population and especially in the A4V subgroup.

We do not interpret these results as showing efficacy, but are encouraged by the strength and consistency of these preliminary findings. Moreover, this trial is significant in 3 other respects. (1) It represents the first ALS trial initiated in a genetically and phenotypically homogeneous population.

Figure 2 Permanent assisted ventilation (PAV)- and tracheostomy-free survival
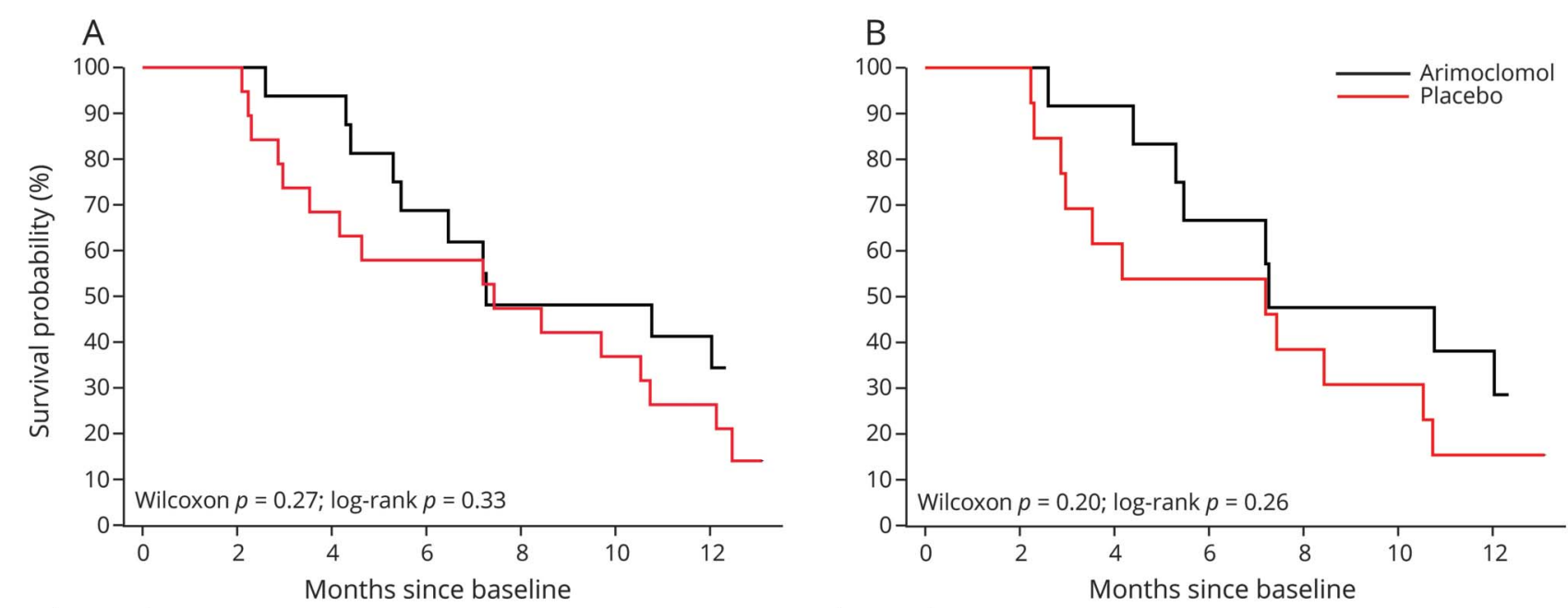

Number at risk:

$\begin{array}{lllllllll} & 17 & 16 & 15 & 10 & 7 & 7 & 6 & \text { Number at risk: }\end{array}$

$\longrightarrow \begin{array}{rrrrrrrrr}17 & 16 & 15 & 10 & 7 & 7 & 6 & 13 \\ 19 & 19 & 13 & 11 & 9 & 7 & 5 & -\quad 13\end{array}$

(A) All arimoclomol- and placebo-treated participants. At 12 months, 34\% of arimoclomol-treated and $<21 \%$ of placebo-treated participants were alive (and without PAV or tracheostomy). (B) The subgroup of A4V participants. At 12 months, 29\% of arimoclomol-treated and $15 \%$ of placebo-treated participants were alive (and without PAV or tracheostomy). 


\begin{tabular}{|c|c|c|c|c|c|c|}
\hline & \multicolumn{3}{|c|}{ All patients $(n=36)$} & \multicolumn{3}{|c|}{ A4V patients only $(n=26)$} \\
\hline & $\begin{array}{l}\text { Placebo } \\
(n=19)\end{array}$ & $\begin{array}{l}\text { Arimoclomol } \\
(n=17)\end{array}$ & $\begin{array}{l}\text { Treatment } \\
\text { difference }^{a}\end{array}$ & $\begin{array}{l}\text { Placebo } \\
(n=13)\end{array}$ & $\begin{array}{l}\text { Arimoclomol } \\
(n=13)\end{array}$ & $\begin{array}{l}\text { Treatment } \\
\text { difference }^{a}\end{array}$ \\
\hline ALSFRS-R slope (points per month) & $-3.0 \pm 0.4$ & $-2.5 \pm 0.4$ & $0.50(-0.63,1.63)$ & $-3.6 \pm 0.5$ & $-2.6 \pm 0.5$ & $0.98(-0.28,2.24)$ \\
\hline FEV6 slope (\% predicted per month) ${ }^{b}$ & $-7.2 \pm 1.3$ & $-6.0 \pm 1.4$ & $1.24(-2.77,5.25)$ & $-8.2 \pm 1.4$ & $-5.5 \pm 1.3$ & $2.71(-1.28,6.70)$ \\
\hline CAFS (rank scores) ${ }^{c}$ & $16.3 \pm 2.4$ & $20.9 \pm 2.5$ & $4.57(-2.50,11.64)$ & $14.5 \pm 2.7$ & $20.5 \pm 2.7$ & $5.92(-1.97,13.81)$ \\
\hline
\end{tabular}

Abbreviations: ALSFRS-R = Revised ALS Functional Rating Scale; CAFS = Combined Assessment of Function and Survival; FEV6 = forced expiratory volume in 6 seconds.

Values presented are mean, \pm SE or mean (95\% confidence interval).

a Treatment difference $>0$ indicates a positive treatment effect of arimoclomol.

${ }^{\mathrm{b}}$ Imputation of 11 missing values due to patient being too ill to perform FEV6 assumes worst-case scenario, in which the missing FEV6 measurements were assumed to have a value of zero. Best-case scenario imputation (based on last observation carried forward) yields similar results.

' Scores range from 1 (worst) to 36 (best).

Although logistically challenging, this approach is both feasible and highly relevant to future trials, as we increasingly recognize the importance of targeting drugs with particular mechanisms of action to patient subpopulations most likely to benefit. (2) This trial pioneered an approach in which safety and efficacy assessments relied heavily on remote assessments. This key design feature helped to mitigate the physical burden of travel to a study center, which can be a major barrier to trial participation. We have also introduced FEV6 to the ALS field and demonstrated its usefulness in reliably quantifying respiratory function; FEV6 may be a useful alternative to vital capacity when the latter cannot readily be obtained. (3) This trial provides the first prospectively acquired natural history data that inform survival in the mutant SOD1 population. Among the placebo-treated patients, median survival from diagnosis was 11.1 months (95\% CI 6.5-13.5) for all SOD1 mutations, and 9.3 months (95\% CI 6.1-12.5) in the A4V subgroup. Similarly, median survival from baseline was 7.4 months (95\% CI 3.0-10.7) and 7.2 months (95\% CI 2.9-10.5), respectively. These estimates are of particular relevance to future therapeutic studies. Moreover, median disease duration (time from symptom onset to survival endpoint) was 17.5 months (95\% CI 11.6-18.4) among all placebo-treated patients, and 13.0 months (95\% CI 6.3-21.3) in the A4V population; these data lend weight to estimates of disease duration based on retrospectively collected data. ${ }^{14,25}$

An important limitation of this trial is the small sample size, which was a function of the ultrarare population targeted for enrollment. We estimate that at most 320 patients across the entire United States could have been considered for the trial over its planned 5-year duration, and this was assuming that all patients would be willing to participate, and without accounting for other eligibility criteria. Moreover, while this study was ongoing, 2 other trials targeting the mutant $S O D 1$ population were also recruiting. ${ }^{26,27}$ Although we successfully enrolled $>10 \%$ of the theoretically eligible population, it was insufficient to permit completion of the planned phase III component of the trial.

The absence of wet biomarker data is another limitation. This reflects the logistical complexity and cost that would have been required to collect, process, and store biological samples from patients who were largely evaluated remotely. Growing interest in developing methods or devices for remote collection of biomarker data might help to mitigate such challenges in future trials.

These data support further development of arimoclomol as a potential therapeutic for ALS. Critical to the design of the next study will be the incorporation of potential pharmacodynamic biomarkers, including those that might show target engagement (e.g., upregulation of HSP). Moreover, it will be essential to explore the use of a higher dose of arimoclomol and to broaden the eligibility criteria to include a more diverse population of patients with ALS, since arimoclomol's mechanism of action is likely to be relevant to all forms of ALS, in which aberrant proteostasis plays an essential role in disease pathophysiology.

\section{Author contributions}

Michael Benatar, $\mathrm{MD}, \mathrm{PhD}$, served as the principal investigator and the site investigator at Emory and University of Miami. He conceived, designed, obtained funding for, and implemented the study. He assisted with results interpretation, prepared the initial draft of the manuscript, and critically edited it for publication. Joanne Wuu, ScM, served as coinvestigator and study statistician. She assisted in the design and implementation of the trial and, together with David Schoenfeld, $\mathrm{PhD}$, was responsible for analysis of data. She critically reviewed and edited the manuscript. Peter M. Andersen, $\mathrm{MD}, \mathrm{PhD}$, performed SOD1 mutation testing and critically reviewed the manuscript for content. Nazem Atassi, $\mathrm{MD}$, served as the site investigator for the trial at the Massachusetts General Hospital. He critically reviewed the manuscript for content. William David, MD, performed motor unit number estimation at the $\mathrm{MGH}$ site. He critically reviewed the manuscript for content. Merit Cudkowicz, MD, served as co-principal investigator on the FDA grant application and served on the trial steering committee. She critically reviewed the manuscript for content. David Schoenfeld, $\mathrm{PhD}$, was principally responsible for the design of the trial and 
served as the lead statistician. He critically reviewed the manuscript for content.

\section{Acknowledgment}

The authors thank the members of the DSMB (Kevin Boylan, $\mathrm{MD}$, Carlayne Jackson, MD, and Michael P. McDermott, $\mathrm{PhD}$ ); the independent medical monitor (Carl Leventhal, $\mathrm{MD})$; members of the trial steering committee (Jeremy Shefner, MD and Christopher Coffey, $\mathrm{PhD}$ ); the study personnel and research pharmacies at both sites; Hong Yu and others at the Neurological Clinical Research Institute Data Management Center at MGH; colleagues around the United States and Canada for referring patients for participation in this study; and the patients who participated in this trial and their families. CytRx Corporation provided the original supply of study drug and matching placebo, and permitted the sponsor-investigator to reference their parent IND. Orphazyme ApS granted permission to continue the use of study drug and to reference their parent IND after acquiring ownership of Arimoclomol from the CytRx Corporation.

\section{Study funding}

The study was sponsored by the ALS Association (grant 1491) and the FDA Orphan Products Development Program (R01 FD003517). Costs of genetic screening were partially supported by Nordic ALS patient organizations, the Swedish Brain Research Foundation, and the Knut and Alice Wallenberg Foundation.

\section{Disclosure}

M. Benatar reports grants from NIH, FDA, CDC, Department of Defense, the ALS Association, the Muscular Dystrophy Association, and Eli Lilly \& Company; research support from Alexion Pharmaceuticals, Cytokinetics, and Neuraltus; and personal fees from Voyager Therapeutics, Ra Pharmaceuticals, Alnylam, Mitsubishi-Tanabe, and Denali outside the submitted work. J. Wuu reports no disclosures. P.M. Andersen reports grants from Knut and Alice Wallenberg Foundation, Swedish Science Council, Swedish Brain research Foundation, Ulla-Carin Lindquist patient organization, Neuroforbundet/NHR patient organization, FFM patient organization, and private donations from patients during the conduct of the study; and personal fees from Biogen Idec USA, Orphazyme ApS, and Remedys Foundation Switzerland outside the submitted work. N. Atassi and W. David report no disclosures. M. Cudkowicz reports grants from FDA during the conduct of the study; and personal fees from Biohaven, Cytokinetics, Eli Lilly \& Company, Voyager, and Mitsubishi Tanabe outside the submitted work. D. Schoenfeld reports grants from NIH during the conduct of the study and personal fees from Orphazyme outside the submitted work. Go to Neurology.org/N for full disclosures.
Received May 8, 2017. Accepted in final form November 9, 2017.

\section{References}

1. Ince PG, Tomkins J, Slade JY, Thatcher NM, Shaw PJ. Amyotrophic lateral sclerosis associated with genetic abnormalities in the gene encoding $\mathrm{Cu} / \mathrm{Zn}$ superoxide dismutase: molecular pathology of five new cases, and comparison with previous reports and 73 sporadic cases of ALS. J Neuropathol Exp Neurol 1998;57:895-904.

2. Bergh J, Zetterstrom P, Andersen PM, et al. Structural and kinetic analysis of proteinaggregate strains in vivo using binary epitope mapping. Proc Natl Acad Sci USA 2015; 112:4489-4494.

3. Bidhendi EE, Bergh J, Zetterstrom P, Andersen PM, Marklund SL, Brannstrom T. Two superoxide dismutase prion strains transmit amyotrophic lateral sclerosis-like disease. J Clin Invest 2016;126:2249-2253.

4. Andersen PM, Al-Chalabi A. Clinical genetics of amyotrophic lateral sclerosis: what do we really know? Nat Rev Neurol 2011;7:603-615.

5. Hargitai J, Lewis H, Boros I, et al. Bimoclomol, a heat shock protein co-inducer, acts by the prolonged activation of heat shock factor- 1 . Biochem Biophys Res Commun 2003;307:689-695.

6. Kalmar B, Burnstock G, Vrbova G, Urbanics R, Csermely P, Greensmith L. Upregulation of heat shock proteins rescues motoneurones from axotomy-induced cell death in neonatal rats. Exp Neurol 2002;176:87-97.

7. Kieran D, Kalmar B, Dick JR, Riddoch-Contreras J, Burnstock G, Greensmith L. Treatment with arimoclomol, a coinducer of heat shock proteins, delays disease progression in ALS mice. Nat Med 2004;10:402-405.

8. Paul S, Mahanta S. Association of heat-shock proteins in various neurodegenerative disorders: is it a master key to open the therapeutic door? Mol Cell Biochem 2014, 386:45-61.

9. Kalmar B, Novoselov S, Gray A, Cheetham ME, Margulis B, Greensmith L. Late stage treatment with arimoclomol delays disease progression and prevents protein aggregation in the SOD1 mouse model of ALS. J Neurochem 2008;107:339-350.

10. Cudkowicz M, Shefner J, Simpson E, et al. Arimoclomol at dosages up to $300 \mathrm{mg} /$ day is well tolerated and safe in ALS. Muscle Nerve 2008;38:837-844.

11. Kim NH, Kim HJ, Kim M, Lee KW. A novel SOD1 gene mutation in a Korean family with amyotrophic lateral sclerosis. J Neurol Sci 2003;206:65-69.

12. Weber M, Neuwirth C, Thierbach J, et al. ALS patients with SOD1 mutations in Switzerland show very diverse phenotypes and extremely long survival. J Neurol Neurosurg Psychiatry 2012;83:351-353.

13. Lindberg MJ, Bystrom R, Boknas N, Andersen PM, Oliveberg M. Systematically perturbed folding patterns of amyotrophic lateral sclerosis (ALS)-associated SOD1 mutants. Proc Natl Acad Sci USA 2005;102:9754-9759.

14. Cudkowicz M, McKenna-Yasek D, Sapp P, et al. Epidemiology of mutations in superoxide dismutase in amyotrophic lateral sclerosis. Ann Neurol 1997;41:210-221.

15. Miano B, Stoddard GJ, Davis S, Bromberg MB. Inter-evaluator reliability of the ALS functional rating scale. Amyotroph Lateral Scler Other Motor Neuron Disord 2004;5: 235-239.

16. Vandevoorde J, Verbanck S, Schuermans D, Kartounian J, Vincken W. FEV1/FEV6 and FEV6 as an alternative for FEV1/FVC and FVC in the spirometric detection of airway obstruction and restriction. Chest 2005;127:1560-1564.

17. Hankinson JL, Crapo RO, Jensen RL. Spirometric reference values for the 6-s FVC maneuver. Chest 2003;124:1805-1811.

18. Fisher LD. Self-designing clinical trials. Stat Med 1998;17:1551-1562

19. Castrillo-Viguera C, Grasso DL, Simpson E, Shefner J, Cudkowicz ME. Clinical significance in the change of decline in ALSFRS-R. Amyotroph Lateral Scler 2010;11: 178-180.

20. Cudkowicz M, Shefner J, Schoenfeld D, et al. A randomized, placebo-controlled trial of topiramate in amyotrophic lateral sclerosis. Neurology 2003;61:456-464.

21. Berry JD, Miller R, Moore DH, et al. The Combined Assessment of Function and Survival (CAFS): a new endpoint for ALS clinical trials. Amyotroph Lateral Scler Frontotemporal Degener 2013;14:162-168.

22. Vonesh E, Greene T, Schluchter T. Shared parameter models for the joint rank analysis of longitudinal data and even times. Stat Med 2006;25:143-163.

23. Atassi N, Berry J, Shui A, et al. The PRO-ACT database: design, initial analyses, and predictive features. Neurology 2014;83:1719-1725.

24. Pocock SJ, Ariti CA, Collier TJ, Wang D. The win ratio: a new approach to the analysis of composite endpoints in clinical trials based on clinical priorities. Eur Heart J 2012, 33:176-182.

25. Bali T, Self W, Liu J, et al. Defining SOD1 ALS natural history to guide therapeutic clinical trial design. J Neurol Neurosurg Psychiatry 2016;88:99-105.

26. Lange DJ, Andersen PM, Remanan R, Marklund S, Benjamin D. Pyrimethamine decreases levels of SOD1 in leukocytes and cerebrospinal fluid of ALS patients: a phase I pilot study. Amyotroph Lateral Scler Frontotemporal Degener 2013;14: 199-204.

27. Miller TM, Pestronk A, David W, et al. An antisense oligonucleotide against SOD1 delivered intrathecally for patients with SOD1 familial amyotrophic lateral sclerosis: a phase 1, randomised, first-in-man study. Lancet Neurol 2013;12:435-442. 


\section{Randomized, double-blind, placebo-controlled trial of arimoclomol in rapidly progressive SOD1 ALS} Michael Benatar, MD, PhD, Joanne Wuu, ScM, Peter M. Andersen, MD, PhD, Nazem Atassi, MD,
William David, MD, Merit Cudkowicz, MD, and David Schoenfeld, PhD

Cite as: Neurology ${ }^{\circledR}$ 2018;90:e565-e574. doi:10.1212/WNL.0000000000004960
Correspondence

Dr. Benatar

mbenatar@med.miami.

edu
Trial registration number: NCT00706147.

\section{Study question}

Is arimoclomol safe and tolerable, and is there preliminary evidence of efficacy, among patients with rapidly progressive SOD1 amyotrophic lateral sclerosis (ALS)?

\section{Summary answer}

Arimoclomol is safe and tolerable at a dose of $200 \mathrm{mg} 3$ times daily (TID) for 12 months. Preliminary efficacy data support further development of arimoclomol as a potential ALS therapeutic.

\section{What is known and what this article adds}

This study provides further evidence (Class II) that arimoclomol is safe and tolerable and provides preliminary evidence of efficacy. It also successfully demonstrates the utility of remote assessment methods.

\section{Participants and setting}

This study examined 36 adult patients ( 23 women, 13 men) with rapidly progressive SOD1 ALS who were enrolled at 3 US academic medical centers between December 2008 and June 2014.

\section{Design, size, and duration}

For this double-blind trial with block randomization and computer-generated allocation, participants were assigned to receive arimoclomol $(n=17)$ or a placebo $(n=19)$ for up to 12 months. Arimoclomol or matched placebo was dispensed in 200-mg TID doses.

\section{Outcomes}

Primary outcomes were safety and tolerability, assessed based on frequencies of adverse events, abnormal vital signs, and abnormal laboratory test results throughout the study period. Secondary outcomes included survival and the rate of decline of the revised ALS Functional Rating Scale.

\section{Main results and the role of chance}

Arimoclomol was safe and well-tolerated (table), with only one participant stopping arimoclomol due to a (probably
Table 1

\begin{tabular}{lll}
\hline Serious Adverse Event & $\begin{array}{l}\text { No. in placebo } \\
\text { group }\end{array}$ & $\begin{array}{l}\text { No. in arimoclomol } \\
\text { group }\end{array}$ \\
\hline Dyspnea & 8 & 7 \\
\hline Respiratory disorders & 2 & - \\
\hline $\begin{array}{l}\text { Upper gastrointestinal } \\
\text { disorders }\end{array}$ & 1 & - \\
\hline Muscle weakness & 1 & - \\
\hline Dysphagia & 3 & - \\
\hline
\end{tabular}

related) skin rash. Point estimates of efficacy outcomes all favored arimoclomol, but with broad confidence intervals, precluding any firm conclusions about treatment benefits.

\section{Bias, confounding, and other reasons for caution}

This study was not powered for efficacy outcomes. The wide confidence intervals around point estimates of efficacy outcome are likely due to small sample size.

\section{Generalizability to other populations}

Safety data are likely to be broadly relevant. While generalizability of the preliminary efficacy results to non-SOD1 and more slowly progressive ALS is less clear, further study in these populations is supported by arimoclomol's mechanism of action.

\section{Study funding/potential competing interests}

This study was funded by the ALS Association and the US Food and Drug Administration, with additional support from the Nordic ALS patient organizations, the Swedish Brain Research Foundation, and the Knut and Alice Wallenberg Foundation. Some authors report receiving research funding from various government agencies, private foundations, and pharmaceutical companies and personal compensation from various pharmaceutical companies and the Remedys Foundation Switzerland. Go to Neurology.org/N for full disclosures. 


\section{Neurology}

\section{Randomized, double-blind, placebo-controlled trial of arimoclomol in rapidly progressive SOD1 ALS}

Michael Benatar, Joanne Wuu, Peter M. Andersen, et al.

Neurology 2018;90;e565-e574 Published Online before print January 24, 2018

DOI 10.1212/WNL.0000000000004960

This information is current as of January 24, 2018

\section{Updated Information \&} Services

References

Subspecialty Collections

Permissions \& Licensing

\section{Reprints}

including high resolution figures, can be found at: http://n.neurology.org/content/90/7/e565.full

This article cites 27 articles, 5 of which you can access for free at: http://n.neurology.org/content/90/7/e565.full\#ref-list-1

This article, along with others on similar topics, appears in the following collection(s):

\section{All Genetics}

http://n.neurology.org/cgi/collection/all_genetics

Amyotrophic lateral sclerosis

http://n.neurology.org/cgi/collection/amyotrophic_lateral_sclerosis_ Class II

http://n.neurology.org/cgi/collection/class_ii

Clinical trials Randomized controlled ( $\overline{\mathbf{C} O N S O R T}$ agreement)

http://n.neurology.org/cgi/collection/clinical_trials_randomized_contro lled_consort_agreement

Information about reproducing this article in parts (figures,tables) or in its entirety can be found online at:

http://www.neurology.org/about/about_the_journal\#permissions

Information about ordering reprints can be found online:

http://n.neurology.org/subscribers/advertise

Neurology ${ }^{\circledR}$ is the official journal of the American Academy of Neurology. Published continuously since 1951, it is now a weekly with 48 issues per year. Copyright @ 2018 The Author(s). Published by Wolters Kluwer Health, Inc. on behalf of the American Academy of Neurology. All rights reserved. Print ISSN: 0028-3878. Online ISSN: 1526-632X.

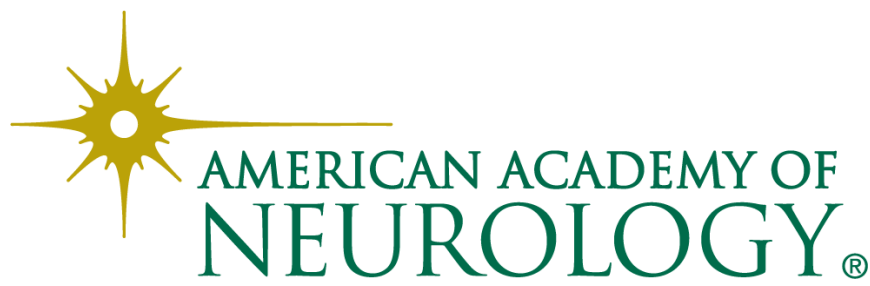

